\title{
CORRUPÇÃO, URBANISMO E IMPROBIDADE ADMINISTRATIVA: UM ESTUDO DE CASO
}

\author{
CORRUPTION, URBAN PLANNING AND ADMINISTRATIVE MISCONDUCT: A CASE \\ STUDY
}

\author{
Rogério Gesta Leal ${ }^{1}$ \\ Carla Luana da Silva ${ }^{2}$
}

\section{Resumo}

O presente ensaio vai tratar do tema que envolve o instituto da improbidade administrativa e seus fundamentos filosóficos, políticos e jurídicos, verificando em que medida ele se relaciona com a moralidade administrativa enquanto princípio constitucional vinculante dos atos da Administração Pública no Brasil, a partir do que analisar-se-á estudo de caso versando sobre improbidade administrativa urbanística julgada pelo Tribunal de Justiça do Estado do Rio Grande do Sul, identificando nele os parâmetros teóricos e normativos anteriormente demarcados. A metodologia utilizada na pesquisa e neste texto foi a dedutiva-indutiva, utilizando-se de referenciais teóricos importantes sobre o tema e analisando caso concreto da jurisdição nacional. Como resultado final da pesquisa e do texto, evidencia-se a importância do instituto jurídico da improbidade administrativa para enfrentar os desmandos que se tem operado no espaço urbano, notadamente envolvendo a corrupção praticada por agentes públicos.

Palavras-chaves: Improbidade Administrativa. Corrupção. Espaço Urbano. Desapropriação Urbana. Administração Pública.

\begin{abstract}
This work will deal with the subject that involves the institute of administrative improbity and its philosophical, political and juridical foundations, verifying in what extent it relates to administrative morality as a binding constitutional principle of the acts of Public Administration in Brazil. From this, the text analyze a case study dealing with administrative impropriety judged by the Court of Justice of the State of Rio Grande do Sul, will be intended identifying in it the theoretical and normative parameters previously demarcated. The methodology used in the research and in this text was the deductive-inductive, using important theoretical references on the subject and analyzing concrete case of the national jurisdiction. As a result of the research and the text, it is evident the importance of the legal institute of administrative improbity to face the evictions that have operated in the urban space, notably involving the corruption practiced by public agents.
\end{abstract}

Keywords: Administrative improbity. Corruption. Urban Space. Urban Expropriation. Public Administration.

\footnotetext{
1 Doutor em Direito pela UFSC e UBA, 2000. Professor Titular da UNISC e da FMP. E-mail: gestaleal@gmail.com

2 Mestranda em Direito na Universidade de Santa Cruz do Sul - UNISC. E-mail: carlaluanaschulz@hotmail.com
} 


\section{INTRODUÇÃO}

O tema da improbidade administrativa no Brasil tem ganhado cada vez mais fôlego em face dos escândalos envolvendo gestores públicos corruptos e Mercado, haja vista que os déficits de controle interno da Administração Pública que temos ao longo da história. Paralelamente a isto, a improbidade de que estamos falando tem cada vez mais vínculos orgânicos com a moralidade administrativa e a ética pública, elementos principiológicos adotados pela Carta Política de 1988.

No plano da gestão urbana, mais especialmente os desmandos que o mercado imobiliário e alguns agentes públicos têm praticado, são de gravidade extrema as consequências da improbidade administrativa, mas o controle jurisdicional tem conseguido, ao menos parcialmente, alcançar tais comportamentos.

Nossa intenção aqui é, portanto, verificar quais os fundamentos filosóficos, políticos e jurídico da improbidade administrativa e como eles se projetam em termos de bens jurídicos protegidos pela Lei Federal brasileira № 10.257, de 10 de janeiro de 2001. Ato contínuo vamos avaliar caso concreto decidido pelo Tribunal de Justiça do Estado do Rio Grande do Sul, por nossa relatoria, envolvendo improbidade administrativa e desapropriação urbana, evidenciando a ocorrência de atos de corrupção de gestor público, justamente para identificar a validade dos elementos teóricos até então esboçados.

\section{ALGUNS FUNDAMENTOS FILOSÓFICOS, POLÍTICOS E JURÍDICOS DA IMPROBIDADE ADMINISTRATIVA}

O agir ímprobo na Administração Pública sempre foi objeto de preocupação no campo da filosofia e da política. Cícero (2001, p.19), na Tribuna do Senado Romano, em 63 a.C., denunciando os atos de corrupção de Sylla, já teve oportunidade de dizer que: "as feridas que possam ser curadas eu quero curá-las. Mas cortarei a fio de espada tudo quanto possa causar a ruína do Estado".

Fazendo um elogio às virtudes da serenidade, da moderação, da sobriedade, da solidez e assiduidade dos sentimentos, Cícero (2001, p.45) já sinalizava o perfil dos que deveriam gestar a coisa pública, partindo do pressuposto de que as pessoas não são perfeitas e é preciso encontrar as virtudes adequadas em face das demandas que se apresentam ao indivíduo e à Sociedade. 
Não estou querendo dizer com isto que se resume a situações comportamentais isoladas a maior ou menor possibilidade de se ter atos ímprobos, mas tão somente que o compromisso efetivo com determinados vetores axiológicos é importante quando se fala de vida em sociedade.

Isto é tão sério e contemporâneo que parte da doutrina italiana sobre Direito Administrativo tem entendido que a corrupção tem se transformado em uma dimensão normal de significativa parte das relações entre instituições e a sociedade, e por isto, representa risco de comprometer a forma constitucional da Democracia. Para tal perspectiva, são os sistemas político, jurídico e social, enquanto unidade, que devem encontrar adequados tratamentos ao fenômeno da corrupção, através de usos integrados e coordenados de seus componentes técnicos e políticos. ${ }^{3}$

A verdade é que a corrupção, sob o plano administrativo, está conectada com questões que dizem à forma e conteúdo de problemas envolvendo a legalidade, correção e bom andamento das instituições e seus funcionários, razão pela qual o incremento somente de normas jurídicas não basta para o tratamento desta patologia, representando, de forma isolada e por vezes, o fracasso das instituições. Como diz Marzuoli (2011, p.2): "I'idea che i problemi si risolvano (innanzitutto) facendo norme innesca una spirale pericolosa. II problema genera il bisogno di nuove norme; la moltiplicazione delle norme aggrava il problema; l'aggravamento del problema induce ulteriore norme, e cosi via".

Por isto impõe-se no enfrentamento da corrupção políticas públicas institucionais unívocas e estáveis em termos de valores e princípios informativos, mas plurais, transparentes, em rede com a Sociedade Civil e o Mercado, visando à mudança de paradigmas culturais que tem favorecido a proliferação de comportamentos corruptivos, maneira mais efetiva de se garantir a capacidade de governo eticamente responsável. ${ }^{4}$

É claro que tais políticas devem ter em conta que a função primordial da Administração é a satisfação de fato dos interesses públicos da comunidade, para o que não pode estar totalmente engessada para os atos de gestão - tomando relevo o significado da

\footnotetext{
3 Refiro-me pontualmente aos trabalhos de: MARZUOLI, Carlo. Fenomeni Corruttivi e Pubblica Amministrazione: più discipline, un unico obiettivo. In: PALAZZO, Francesco. (a cura di). Corruzione Pubblica. Firenze: Firenze University Press, 2011; MATTARELLA, Bruno. Le regole dell'onestà. Bologna: Daltricce, 2012; MERLONI, F; VANDELLI, L. (a cura di). La corruzione amministrativa: cause, prevenzione e rimedi. Firenze: Firenze University Press, 2010.

${ }^{4}$ Daí que divirjo de Marzuoli (2011, p.03) quando defende a ideia de que, por vezes, afigura-se necessária a constituição de uma administração de emergência (amministrazione dell'emergenza), enquanto "amministrazione aggiuntiva e parallela, peraltro con più estesi poteri, le ordinanze in deroga, e con minori controlli", sob pena de se estar criando novas estruturas burocráticas de poder e de corrupção.
} 
discricionariedade no ponto. É deste fim último que a Administração extrai as condições de possibilidades de sua legitimidade institucional e política, a qual, uma vez violada, autoriza medidas curativas e preventivas. Aliás,

il carattere vincolato dell'attività neppure è un rimedio sicuro; può rendere più laboroso il fenomeno corrutivo, ma può anche sevire meglio occultarlo attraverso una regolarità che, per essere puramente cartacea e formale, erige speso uno schermo difficilmente superabile (MATTARELLA, 2012, p.19).

Significa dizer, com isto, que este fenômeno da corrupção tem de ser compreendido em toda a extensão de suas causas e consequências, uma vez que atinge de maneira letal múltiplos e distintos bens jurídicos ao mesmo tempo: de um lado, o interesse e patrimônio (material e imaterial) públicos, de outro, o plexo axiológico-normativo regulador de condutas individuais e coletivas do sistema jurídico vigente, em especial do agente público.

Uma evidência clara disto decorre das diferenças gritantes entre os indicadores, pesquisas, dados estatísticos, nacionais e internacionais, dando conta do aumento das patologias corruptivas no mundo, e a correlata percepção social baixíssima disto, evidenciando o que se pode chamar de caráter submerso do fenômeno corruptivo.

Nestes cenários, os centros institucionais de poder podem desenvolver protagonismo diferenciado - tanto a favor como contra a corrupção -; e o problema é quando funciona como garante dos ilícitos praticados, inclusive contribuindo à regulação dos complexos mecanismos corruptivos, operando até como "terminali delle tangenti pagate dagli imprenditori" (VANNUCI, 2003, p. 37)..$^{5}$ Estes mecanismos, quando sofisticados e operados com inteligência corporativa vão criando redes colaborativas que mascaram e mesclam as condutas corruptas e seus resultados com iniciativas lícitas ordinárias (lavagem de dinheiro e criminalidade econômica lato senso), por exemplo.

Daqui advém a discussão da moralidade administrativa, exatamente vinculada à questão daqueles valores e princípios albergados normativamente pelo sistema jurídico - em especial a ordem constitucional.

\footnotetext{
${ }^{5}$ Como quer VANNUCCI, Antonio. La corruzione nel sistema político italiano a dieci anni da mani pulite. In: FORTI, Gabrio (a cura di). Il prezzo della tangente: la corruzione come sistema a dieci anni da mani pulite. Milano: Vita e Pensiero, 2003, p.37, este pagamento nem sempre é em espécie, como bem lembra o autor, pois "è frequente che l'imprenditore adempia al patto corrutivo secondo paradigmi diversi non sempre riconducibili alla mera dazione di denaro: cosi, ad esempio, si pensi all'impreditore che adempie al patto corruttivo contribuendo in vario modo al consolidamento del consenso político atraverso il finanziamento di iniziative di partito, oppure garantendo l'assunzione nell'azienda del personale segnalato dai politici".
} 
Na França do século XX, Morin (1990) e Ripert (1984) se empenharam em demonstrar que o Direito não se resume a conceitos jurídicos, mas necessariamente suas normas irão refletir objetivos políticos, econômicos, sociais, afigurando-se como importante marco divisor em face das correntes positivistas então hegemônicas que se esforçavam em retirar todo e qualquer valor ideológico e axiológico das normas jurídicas. Ripert (1984) chamava atenção para o fato de que a relação entre Direito e Moral é um problema jurídico que predomina na elaboração das leis pelo legislador, em sua interpretação e aplicação, razão pela qual a força das leis somente advinha quando houvesse respeito aos ideais morais relevantes para determinada sociedade em determinado momento histórico. Na mesma direção vai Paolo (1995, p.690), ao dizer que:

in countries with systemic political and administrative corruption, the formal legal framework of the state is insufficient as terms of reference to assess and judge the problem of corruption. Thus, the degenerative effects of political corruption cannot be counteracted by a legalistic or administrative approach alone. Moral, normative, ethical, and indeed political benchmarks will have to be brought in. Endemic corruption calls for radical political reforms, a system of checks and balances, and deep democratization. ${ }^{6}$

De forma mais contemporânea a doutrina brasileira contou com a sobriedade e ilustração do Prof. Manoel de Oliveira Franco Sobrinho que, em 1974, editou texto abordando especialmente o tema da moralidade administrativa e seu controle (SOBRINHO, 1993). Lembra o autor que a causa do ato administrativo se afigura como sua base fundante, vinculando a decisão administrativa às situações objetivas ensejadoras do ato em si como do Direito

\footnotetext{
${ }^{6}$ Adverte o autor ainda que: "Without understanding the roles of the state, it is difficult to understand why corruption occurs. The main lines of argument may be simplified in the following way: (1) Any potential, isolated market transaction is inherently loaded with conflict, and may be portrayed as a prisoner's dilemma game. Depending on the exact circumstances of the transaction, stealing/cheating or robbing is the dominant strategy. Anthropological field studies have described a number of cases where conflicts have arisen in trade between social units where the members are not known across the units. If the traders know that the trades will be repeated, and they know each other through some kind of family or ritual friendship networks, other equilibrium are conceivable and encounter with economic content may become regular. To personalize the transaction is the first way to solve the conflict and build trust among the traders. (2) Any modern market-based economy has such a scale that a large number of transactions have to be made as impersonal encounters between traders, or, for that matter, between traders and a government. While modern traders also try to build personalized networks, there are limits to how extensive these may become. That is, isolated, impersonalized encounters are a necessary part of any extensive economic development. But then we are often backing to the simple prisoner's dilemma game. (3) If certain norms of honesty in impersonal transactions were internalized and could be shown to be self-sustaining, it will make the social order problem of market encounters easier to solve. One way to visualize this is to make conscience, internalized social norms substitute for the values of cheating in the impersonal".
} 
aplicado. Assim sendo, a inexistência ou ilegalidade de causa, tanto jurídica como material, conduz à conclusão de não-moralidade administrativa.

O que está em debate também aqui são as causas fundantes justificadoras do ato administrativo, ampliando mais a reflexão e base argumentativa do conceito de moralidade pública juridicamente conformada, para além, pois, do vínculo que a doutrina nacional e internacional tem estabelecido desta categoria com o conceito de Boa Administração!

Mas o que caracteriza esta Boa Administração no caso Brasileiro?

Já tive oportunidade de dizer em trabalho anterior que o país conta hoje com indicadores constitucionais parametrizantes de Boa Administração, os quais não podem ser desconsiderados em quaisquer ações - públicas ou privadas. Tais indicadores, em síntese, dizem respeito à construção de uma Sociedade livre, justa e solidária; à garantia o desenvolvimento nacional; à erradicação da pobreza e da marginalização, bem como à redução das desigualdades sociais e regionais; à promoção do bem de todos, sem preconceitos de origem, raça, sexo, cor, idade e quaisquer outras formas de discriminação (LEAL, 2009). ${ }^{7}$

A densificação mais objetiva e precisa destes indicadores pode ser encontrada ao longo de todo o Texto Político, consubstanciando-se nos direitos e garantias fundamentais, individuais e coletivos, nos direitos sociais, nos direitos à educação, à saúde, à previdência, etc. Por sua vez, os Poderes Estatais e a própria Sociedade Civil (através da cidadania ou mesmo de representações institucionais dela) estão jungidos a estes indicadores norteadores da República, eis que eles vinculam todos os atos praticados pelos agentes públicos e pela comunidade, no sentido de vê-los comprometidos efetivamente com a implementação daquelas garantias. ${ }^{8}$

Para cada plexo de garantias outorgadas à responsabilidade estatal vista, necessitam advir políticas públicas concretizadoras, que se operam em diversos níveis de efetivação, tais como os da elaboração, constituição formal, execução e avaliação das ações necessárias, contando para tanto com a máxima participação da comunidade alcançada por elas; e em todas elas o risco da corrupção é premente.

Quando estas políticas públicas ou ações estratégicas dos Poderes competentes não ocorrem, ou ocorrem de forma desviada da finalidade pública e/ou contaminadas por

\footnotetext{
7 Ver também o texto LEAL, Rogério Gesta. Perspectivas do direito adquirido constitucional contra o Estado Democrático de Direito. Revista do Direito n. 23, Santa Cruz do Sul - Editora da UNISC. 2006.

8 Ver ainda os textos de FREITAS, Juarez. Discricionariedade Administrativa e o Direito Fundamental à Boa Administração Pública. São Paulo: Malheiros, 2007; MUÑOZ, Jaime Rodriguez-Arana. La Dimensión Ética. Madrid: Dykinson, 2001.
} 
patologias corruptivas, o Poder Judiciário é chamado à colação, daí porque a Administração haverá de proceder em relação aos administrados com sinceridade e Ihaneza, sendo-lhe interdito qualquer comportamento astucioso, eivado de malícia, produzido de maneira a confundir, dificultar ou minimizar o exercício de direitos por parte dos cidadãos (MELLO, 2001, p119.). ${ }^{9}$

Ou seja, a moralidade administrativa não se resume a uma premissa ideológica, subjetiva, mas trata-se de conceito jurídico objetivo por estar inserido na ordem legal, prendendo-se à estrutura funcional do Estado e à legitimidade da própria função administrativa (SOBRINHO, 1993, p. 4). Vai à mesma direção Silva (2010, p.563), ao sustentar que "a moralidade administrativa não é meramente subjetiva, porque não é puramente formal, porque tem conteúdo jurídico a partir das regras e princípios da Administração. A lei pode ser cumprida moralmente ou imoralmente".

Este conceito jurídico objetivo fornece ao sistema normativo verdadeiros standards de Boa Administração passíveis de densificação material a aplicação prática nos casos concretos dos atos administrativos, o que potencializa os controles da Administração Pública em muito, isto é,

a Administração e seus agentes têm de atuar na conformidade de princípios éticos. Violá-los implicará violação ao próprio direito, configurando ilicitude, que assujeita (sic) a conduta viciada à invalidação porquanto tal princípio assumiu foros de pauta jurídica, na conformidade do art. 37 da Constituição (MELLO, 2001, p.119).

Com base em tais premissas, ganha força o argumento de Di Pietro (2000), no sentido de que não é preciso penetrar na intenção do agente público para nela perscrutar sobre a moralidade administrativa de seu comportamento, isto porque do próprio objeto deste pode ser aferida a imoralidade. Assim, Di Pietro (2000, p.111) relaciona que "a moralidade exige proporcionalidade entre os meios e os fins a atingir, entre os sacrifícios impostos à coletividade e os benefícios por ela auferidos; entre as vantagens usufruídas pelas autoridades públicas e os encargos impostos à maioria dos cidadãos".

O vínculo forte que esta moralidade administrativa mantém com a ideia de Boa Administração diz com o fato de criar à Sociedade verdadeiro direito subjetivo de ter uma

\footnotetext{
${ }^{9}$ Correto o autor a dizer que os princípios da boa-fé, da lealdade administrativa e o da proibição do enriquecimento sem causa da Administração, se extraem do princípio da moralidade administrativa. Ver também os textos: MELLO, Celso Antonio Bandeira de. Curso de Direito Administrativo. São Paulo: Malheiros, 2010; Discricionariedade e Controle Judicial. São Paulo: Malheiros, 2000; Legalidade, Motivo e Motivação do Ato Administrativo. In: Revista de Direito Público n. 90/57; Controle Judicial dos Atos Administrativos. In: Revista de Direito Administrativo, n. 152/01; . $\mathrm{O}$ Desvio de Poder. In: Revista de Direito Administrativo, n. 172/1, 1988.
} 
gestão pública compromissada com aqueles vetores comportamentais, bem como contar com mecanismos eficientes de participação e controle das ações públicas.

Mas então qual seria a relação entre moralidade administrativa e improbidade administrativa? A imoralidade administrativa seria o gênero do qual a improbidade pode ser considerada espécie, uma das formas de manifestação da primeira (SILVA, 2010, p.564).

E quais os remédios para comportamentos deste jaez? Como se têm postos os marcos regulatórios neste particular?

É de se notar que a Organização para a Cooperação e Desenvolvimento Econômico OCDE, em 1997, tratou destes temas a partir da perspectiva da Ética Pública, sustentando que as possibilidades de efetividade da ética pública demandam condições materiais adequadas, dentre as quais:

a. apoio e compromisso políticos dos agentes públicos;

b. marcos normativos adequados;

c. mecanismos de formação e de socialização dos servidores públicos;

d. códigos de conduta específicos aos agentes públicos;

e. mecanismos de imputação e responsabilidade efetivos;

f. condições de trabalho para os agentes públicos;

g. existência de uma sociedade civil ativa e participante; e

h. sistemas de controle interno e externo da gestão pública coordenados e eficientes. ${ }^{10}$

Veja-se que, antes disto, já em 1994, o informe NOLAN, elaborado pelo Presidente da Comissão do Parlmento britânico, a pedido do então Primeiro Ministro deste país, esboçou sete princípios de condutas à vida pública, a saber:

a. os que ocupam cargos públicos deveriam tomar decisões somente com fundamento e foco no interesse público;

b. estes agentes públicos não deveriam ter nenhuma relação financeira ou de outra ordem de privilégios com terceiros ou organizações que possam influir no desempenho de suas responsabilidades oficiais;

\footnotetext{
${ }^{10}$ Ver o texto da Organização para a Cooperação e Desenvolvimento Económico - OCDE. La Ética en el servicio público - cuestiones y prácticas actuales. Madrid: Ministerio de Administraciones Públicas/ Instituto Nacional de Administración Pública - INAP. Disponível em: <http://www.inap.org.mx/portal/images/RAP/la\%20etica\%20en\%20el\%20servicio\%20publico.pdf>. Acesso em: 16 jan. 2013, p.29. Diz que: "Durante la década de los noventa se realizaron de manera bianual diferentes Conferencias Internacionales Sobre Ética en el Gobierno. En 1997 se realizó en Lima (Perú) la Octava Conferencia Internacional de Ética en el Gobierno; en 1999 se celebro en Durbán (Sudáfrica) la novena conferencia; en 2001, se realizó la décima en Praga (República Checa) mientras que en el 2003 fue Seúl (Corea del Sur) la sede de la undécima".
} 
c. na gestão dos assuntos públicos incluindo aí as nomeações para cargos públicos, a contratação de indivíduos deveria se dar por critérios meritocráticos e legais;

d. os que ocupam cargos públicos são responsáveis por suas decisões e açõem em face da Sociedade, e devem se submeter ao controle apropriado aos seus cargos;

e. os que ocupam cargos públicos deveriam trabalhar da forma mais aberta possível em todas as decisões que tomam e em todas as ações que realizam, justificando-as de forma clara e fundamentada;

f. os que ocupam cargos públicos têm a obrigação de declarar todos os interesses privados relacionados com suas responsabilidades, bem como tomar medidas para solucionar qualquer conflito que surja, protegendo sempre o interesse público;

g. os que ocupam cargos públicos deveriam fomentar e apoiar estes princípios com liderança e exemplo (CORTINA, 1998).

O Comitê PUMA da OCDE, em maio de 1998, se ocupou de demarcar recomendações à ética no serviço público, dentre os quais: que deveriam ser muito claras e fundadas no ordenamento jurídico, devendo existir compromisso e liderança política que reforce e apoie a conduta ética dos servidores públicos; que o processo de tomada de decisões seja transparente a ponto de permitir a informação suficiente à Sociedade, bem como eventual investigação sobre eles; da mesma forma as linhas mestras da relação entre setor público e privado devem ser claras e precisas; que as políticas de gestão, os procedimentos e as práticas administrativas devem seguir e incentivar condutas éticas; é preciso contar com mecanismos adequados de responsabilidade para o serviço público, fixando-se procedimentos e sanções disciplinares adequadas às condutas irregulares.

Nesta mesma década começam a surgir diversas manifestações de governos com o fim de instrumentalizar a ética pública em suas respectivas administrações. Em 1991, os Estados Unidos da América criou o Conselho Presidencial para a integração e eficiência; em 1992, o Ministério da Justiça e Administração Governamental da Noruega designou um grupo operativo para a investigação dos níveis de corrupção e à restauração da ética no serviço público; no mesmo ano o Ministério do Interior da Holanda estabeleceu como meta central de atuação o fortalecimento da integridade na administração pública; em 1996 foi a vez da Austrália criar um guia de elementos-chaves sobre responsabilidade ministerial, que serviu de referência para os princípios, convenções e regras de conduta das pessoas situadas em postos ministeriais (ESPINOSA, 2004, p.39). 
Por fim, no Brasil, em termos de importância destacada na matéria, foi promulgada, também na década de 1990 (02 de junho de 1992), a lei regulamentadora do $§ 4^{\circ}$, do artigo 37, da Constituição de 1988, a saber, a Lei Federal n8.429 (Lei da Improbidade Administrativa LIA), dispondo sobre as sanções aplicáveis aos agentes públicos nos casos de enriquecimento ilícito no exercício de mandato, cargo, emprego ou função na administração pública direta, indireta ou fundacional, revogando expressamente (art.25) as citadas Leis $n^{\circ} 3.164 / 1957$ e $3.502 / 1958$.

Nos termos da Lei referida, ao menos em linhas gerais, há três tipos de atos administrativos de improbidade: a) atos de improbidade administrativa que importem em enriquecimento ilícito; b) atos de improbidade que causem prejuízo ao erário; c) atos de improbidade que atentem contra os princípios da administração pública, matéria que passo a aprofundar agora a partir da análise tópica deste marco normativo infraconstitucional regulador da improbidade administrativa, os quais passo a analisar de forma mais detalhada em alguns dos seus aspectos que interessam a esta abordagem.

\section{QUAL O PATRIMÔNIO JURÍDICO PROTEGIDO PELA LEI DE IMPROBIDADE ADMINISTRATIVA NO BRASIL?}

Pelo que até agora referi, concordo com Figueiredo (1999), quando sustenta que a probidade é espécie do gênero moralidade administrativa - ao menos na percepção mais ampliada (filosófica, política e institucional) que demarco neste texto, e a que alude o art. 37, caput e seu §4으, da CF, isto porque o núcleo da probidade está associado ao princípio da moralidade administrativa. Por certo que, com isto, não se está a afirmar "que ambos os conceitos são idênticos. Ao contrário, a probidade é peculiar e específico aspecto da moralidade administrativa" (FIGUEIREDO, 1999, p. 38).

Por tais razões e segundo Pazzaglini Filho, Rosa e Fazzio Júnior (1999, p.60),

no exame dos atos de improbidade administrativa, é crucial que se levem em conta não apenas os princípios informativos explícitos, mas também os implícitos, para que se caracterize a efetiva deformação funcional e reste à calva o intuito final do agente público ímprobo.

Em face desta amplitude do conceito de moralidade administrativa é que a Lei n요.429, de 02 de junho de 1992, trata das sanções a servidores públicos em face de enriquecimento ilícito no exercício de seus cargos, caracterizando o cometimento de tais atos como de natureza administrativa, criminal e político-civil, asseverando Di Pietro (2000, p. 324) que: 
a natureza das medidas previstas no dispositivo constitucional está a indicar que a improbidade administrativa, embora possa ter consequências na esfera criminal, com a concomitante instauração de processo criminal (se for o caso) e na esfera administrativa (com a perda da função pública e a instauração de processo administrativo concomitante) caracteriza um ilícito de natureza civil e política, porque pode implicar a suspensão dos direitos políticos, a indisponibilidade dos bens e o ressarcimento dos danos causados ao erário.

Isto é tão certo que a Lei 8.429/92 apresenta, linhas gerais, três modalidades de atos de improbidade administrativa, quais sejam, os que importam enriquecimento ilícito, os que causam dano ao erário e os que atentam contra os princípios da Administração Pública, o que, em face da abrangência destas possibilidades, configuram hipóteses delitivas abertas a múltiplas concreções, notadamente diante da demarcação do conceito de dano ao erário e violação de princípio da Administração.

Isto não significa, a meu sentir, que a legislação, ao não criar uma definição fechada à improbidade administrativa, tenha dado um cheque em branco ou ato de prepotência aqueles que tem o dever de aplicá-la (como o Ministério Público), isto porque a intenção do legislador foi exatamente ampliar o leque de investigação e sancionamento de atos ilícitos corruptivos, garantindo todos os direitos de defesa assegurados pelo ordenamento jurídico.

A Lei de Improbidade nos seus artigos 1ํ, 2ํㅡ, 3ำ, definem quem são os sujeitos ativo e passivo do ato de improbidade, sendo estes quaisquer entidades públicas ou particulares que tenham participação de dinheiro público em seu patrimônio ou receita anual, entrando neste rol a administração direta e indireta (autarquias, sociedades de economia mista e fundações); a empresa incorporada ao patrimônio público; entidade para cuja criação ou custeio o erário haja concorrido ou concorra com mais de 50\% do patrimônio ou da receita anual; entidade para cuja criação ou custeio o erário haja concorrido ou concorra com menos de 50\% do patrimônio ou da receita anual; entidade que receba subvenção, benefício ou incentivo, fiscal ou creditício, de órgão público.

Já o sujeito ativo é o agente público, nos termos da definição lançada pelo art. 2ํㅡ, da Lei 8.429/92, ou seja, "todo aquele que exerce, ainda que transitoriamente ou sem remuneração, por eleição, nomeação, designação, contratação ou qualquer outra forma de investidura ou vínculo, mandato, cargo, emprego ou função" nas entidades mencionadas no seu art. 1‥ Vai mais longe a norma, deixando claro que busca alcançar todos que com a Administração Pública mantém vínculo, eis que define igualmente como sujeito ativo aquele que, mesmo não sendo 
agente público, induza ou concorra para a prática do ato de improbidade ou dele se beneficie sob qualquer forma direta ou indireta. ${ }^{11}$

Os atos que importam enriquecimento ilícito, descritos no art.9ำ, não deixam dúvidas quanto ao núcleo de suas condutas tipificadoras ser a obtenção de vantagem econômica, o que se evidencia gramaticalmente pelos vermos receber, perceber, aceitar, utilizar, usar, adquirir e incorporar, demandando às suas caracterizações a forma dolosa do comportamento.

Por outro lado, os atos que implicam dano ao erário, dispostos no art.10, remetem à indagação sobre o conceito de Erário Público, e aí é importante se ter claro que diz tão somente com os aspectos econômico-financeiros do patrimônio público, vinculado estritamente ao tesouro, portanto, mais restrito do que a noção de patrimônio público em sentido lato, que é muito mais amplo do que as questões diretamente monetárias. Digo isto porque a Lei sob comento, em seu art.21, vai afirmar que a aplicação das sanções que prevê não depende da efetiva ocorrência de dano ao patrimônio público, fazendo menção, aqui, a todos os aspectos monetários, estéticos, artísticos, paisagísticos, morais, históricos, etc. -, que envolvem o interesse público instalado, sendo certo, todavia, que as modalidades insertas no art.10, dependem, para sua configuração, de efetiva lesão aos cofres públicos e não simples e genericamente ao patrimônio público.

Por fim, os atos que atentam contra os princípios da administração pública, insertos no art.11, fazendo referência explícita às ações ou omissões que violarem os deveres de honestidade, imparcialidade, legalidade, e lealdade às instituições, e, de forma indireta, a todos os demais princípios (constitucionais e infraconstitucionais) impostos à Administração, a meu sentir são os mais fragilizados em termos proteção, não só porque se apresentam de forma mais aberta em termos de atribuição de sentido ${ }^{12}$, mas fundamentalmente porque os Tribunais têm dificultado a sua punição quando, por exemplo, o Superior Tribunal de Justiça reclama a presença do elemento subjetivo à caracterização da improbidade administrativa, tendo em vista que ela se resume em uma imoralidade qualificada. Sendo assim, a má-fé deve ser identificada, pois do contrário haverá atipicidade de conduta, tendo em vista que a boa fé é a antítese do ato

\footnotetext{
11 Uma parte da doutrina, como PAZZAGLINI FILHO, M; ROSA, M. F. E; FAZZIO JÚNIOR, W. Improbidade Administrativa: aspectos Jurídicos da defesa do Patrimônio Público. São Paulo: Atlas, 1999, p. 45, tem sustentado que a expressão 'no que couber' deixa claro que, ao terceiro, não se aplicará a sanção da perda de função pública, desde que não a tenha.

${ }^{12}$ Como bem alerta GARCIA E; ALVES, R. Improbidade administrativa. Rio de Janeiro: Lúmen Júris, 2002, p.210, além da tipologia eminentemente aberta constante do caput do art. 11, idêntica técnica legislativa foi adotada na confecção dos incisos do referido dispositivo, alcançando um vasto espectro de atos ilícitos praticados pelos agentes públicos.
} 
imoral e devasso ${ }^{13}$; ademais, na percepção deste Tribunal, o objetivo da LIA é punir o administrador público desonesto e não o inábil ou incompetente:

Recurso Especial. Administrativo. Ação de Improbidade Administrativa. Lei 8.429/92. Ausência de dolo. Improcedência da ação. 1 . O ato de improbidade, na sua caracterização, como de regra, exige elemento subjetivo doloso, à luz da natureza sancionatória da Lei de Improbidade Administrativa. 2. A legitimidade do negócio jurídico e a ausência objetiva de formalização contratual, reconhecida pela instância local, conjura a improbidade. 3. É que "o objetivo da Lei de Improbidade é punir o administrador público desonesto, não o inábil. Ou, em outras palavras, para que se enquadre o agente público na Lei de Improbidade é necessário que haja o dolo, a culpa e o prejuízo ao ente público, caracterizado pela ação ou omissão do administrador público." (Mauro Roberto Gomes de Mattos, em "O Limite da Improbidade Administrativa", Edit. América Jurídica, 2a ed. ps. 7 e 8). "A finalidade da lei de improbidade administrativa é punir o administrador desonesto" (Alexandre de Moraes, in "Constituição do Brasil interpretada e legislação constitucional", Atlas, 2002, p. 2.611)."De fato, a lei alcança o administrador desonesto, não o inábil, despreparado, incompetente e desastrado" (REsp 213.994-0/MG, 1a Turma, Rel. Min. Garcia Vieira, DOU de 27.9.1999)." (REsp 758.639/PB, Rel. Min. José Delgado, 1.a Turma, DJ 15.5.2006) 4. A Lei 8.429/92 da Ação de Improbidade Administrativa, que explicitou o cânone do art. $37, \S 4$ o da Constituição Federal, teve como escopo impor sanções aos agentes públicos incursos em atos de improbidade nos casos em que: a) importem em enriquecimento ilícito (art.9o); b) que causem prejuízo ao erário público (art. 10); c) que atentem contra os princípios da Administração Pública (art. 11), aqui também compreendida a lesão à moralidade administrativa. 5. Recurso especial provido (STJ, Rel. Min. Luiz Fux, REsp n.으 734984/SP, 1a T., DJ de 16.06.2008, grifos próprios).

Andou mal a Corte, pois parece esquecer o que dispõe os arts.3 e 4ํㅡ, da norma, quando asseveram de forma clara que as suas disposições são aplicáveis àquele que, mesmo não sendo agente público, induza ou concorra para a prática do ato de improbidade ou dele se beneficie sob qualquer forma direta ou indireta; e, ademais, que os agentes públicos, de qualquer nível ou hierarquia, são obrigados a velar pela estrita observância dos princípios de legalidade, impessoalidade, moralidade e publicidade no trato dos assuntos que the são afetos. Se a norma tem tal abrangência em termos de sujeitos passivos, como sustentar a justificativa de exculpar atos culposos nesta seara, aceitando implicitamente a hipótese de que o desconhecimento da Lei afasta a responsabilidade do agente?

De que vale o Decreto ㄲo 1.171, de 22 de junho de 1994 (Código de Ética Profissional do Servidor Público Civil do Poder Executivo Federal), estabelecer, no Capítulo I, Seção I, de seu Anexo, que: a dignidade, o decoro, o zelo, a eficácia e a consciência dos princípios morais são

${ }^{13}$ Ver a decisão STJ. Rel. Min. Luiz Fux, REsp no 1023904/RJ, 1a T., DJ de 03.08.2010. 
primados maiores que devem nortear o servidor público, seja no exercício do cargo ou função, ou fora dele, já que refletirá o exercício da vocação do próprio poder estatal. Seus atos, comportamentos e atitudes serão direcionados para a preservação da honra e da tradição dos serviços públicos (I); o servidor público não poderá jamais desprezar o elemento ético de sua conduta. Assim, não terá que decidir somente entre o legal e o ilegal, o justo e o injusto, o conveniente e o inconveniente, o oportuno e o inoportuno, mas principalmente entre $\mathrm{o}$ honesto e o desonesto, consoante as regras contidas no art. 37, caput, e $\S 4^{\circ}$, da Constituição Federal (II)?

Insisto, o objeto de proteção da LIA é amplo, dizendo com patrimônio moral e institucional que não pode ser depredado por condutas negligentes, imperitas ou imprudentes, não se podendo aplicar à espécie a mesma lógica restritiva do dolo penal à configuração da improbidade. E isto porque todos os servidores têm a obrigação de conhecer os limites de suas ações sob o manto da legalidade, honestidade, transparência e responsabilidade, não podendo escusar-se de tal sob o argumento de desconhecimento da lei, o seu cumprimento parcial, como que podendo haver tolerância a atos de menor potencial lesivo à moralidade pública e aos seus princípios normativos vinculantes.

Feitos estes apontamentos, cumpre agora verificar como as relações que se estabelecem entre a improbidade administrativa e os atos corruptivos praticados no âmbito da gestão urbana.

\section{IMPROBIDADE ADMINISTRATIVA E ATOS CORRUPTIVOS URBANÍSTICOS: UM ESTUDO DE CASO}

Em primeiro lugar é preciso que se tenha claro que o tema do Direito Urbanístico no Brasil tem tomado o seu devido lugar de relevo no âmbito do conhecimento jurídico e político dos operadores do direito nos últimos tempos, notadamente a partir da edição do Estatuto da Cidade (Lei Federal no 10.257, de 10 de julho de 2001), que revigorou o debate e a reflexão sobre a matéria.

Ocorre que, neste processo, tem-se percebido que muito há que maturar e compreender, tanto em face de sua natureza fenomenológica e polissêmica das questões urbanas, constituídas que estão de múltiplos saberes e experiências, como em razão da complexidade das relações sociais que encerra. 
A matéria versada aqui tem tratamento normativo esquadrinhado, preliminarmente, pelo texto constitucional brasileiro em vigor, mais especialmente pelo que dispõe o art.30, 174, e seguintes, mais o art.182, e seguintes, eis que versam sobre a ordem econômica e urbana em face das competências do Poder Público local.

Neste diapasão, mister é reconhecer que a propriedade urbana no país, a partir notadamente da norma constitucional vigente, é instituto jurídico cuja definição corresponde a um conjunto transdisciplinar de interesses e matérias, jurídicas ou não.

Num plano mais geral e tradicional, posso aqui afirmar que o conteúdo inerente à propriedade urbana é o circunscrito pelos chamados limites positivos que fixam o elenco de poderes e faculdades do titular do direito e o alcance do respectivo exercício, bem como até onde aquele pode ir na realização de tais poderes e faculdades. De outra banda, há conteúdo negativo, circunscrito pelos limites que estabelecem até onde podem ocorrer ingerências e tangenciamentos de terceiros em relação ao direito alheio, quais os poderes e faculdades de que não dispõe seu titular e aonde esse não pode ir no exercício do direito ${ }^{14}$.

Por estas razões, a legislação, ao estabelecer tais limites, tem imposto ao titular do direito um fazer (conservar o prédio urbano), um não-fazer (não usar nocivamente a propriedade imobilizada em detrimento dos vizinhos) ou um "suportar" (o vizinho pode entrar no terreno limítrofe para reparar o muro divisório) ${ }^{15}$.

Assim é que os limites positivos e negativos do próprio conteúdo do direito, e as limitações ao seu exercício, estabelecidas pelas regras jurídicas, formam o seu estatuto (HEDEMANN, 1987, p. 139), não podendo ser de todo absoluto, eis que tal conteúdo e exercício têm de possibilitar sua coexistência com outros direitos. O poder ou a faculdade do exercício se inscreve, pois, no conteúdo do direito e, se ele é irregular ou danoso, há ilicitude, o que o sistema jurídico não pode aceitar (GANDOLFO, 1970).

\footnotetext{
${ }^{14}$ Para contribuição, ver o trabalho de ARONE, Ricardo. Por uma nova hermenêutica dos direitos reais limitados. Rio de Janeiro: Renovar, 2001.

${ }^{15}$ Por óbvio que estou falando aqui de perspectiva dogmática da matéria trazida pela história de grande parte da abordagem civilista do tema no Brasil e outros países com semelhante formação jurídica. Neste sentido, ver os trabalhos de AZEVEDO, Filadelfo. Destinação do imóvel. São Paulo: Max Limonad, 1957; BRANCA, Giuseppe. Della Proprietà (arts. 957-1099). Bolonha: Zanichelli, 1957; DANTAS, Santiago. O Conflito de Vizinhança e sua Composição. Rio de Janeiro: Globo, 1939; GONÇALVES, Luiz da Cunha. Tratado de Direito Civil. São Paulo: Limonad, 1956. Para boa parte destes autores o mau uso da propriedade vinha definido pelo costume do lugar ou pela extensão do prejuízo causado. Em outras palavras: "Se o incômodo excede ao que é razoavelmente tolerável, segundo as circunstâncias, haverá mau uso da propriedade". BENVILÁQUA, Clóvis. Direito das Coisas. Rio de Janeiro: Forense, 1956, p.74.
} 
Assim, não existe imutabilidade em questão de poderes, de faculdades, em termos de conteúdo e de exercício de direitos - tampouco aos atinentes à propriedade urbana no Brasil. Em decorrência disto, as alterações no estatuto do direito de propriedade, a imposição de novas limitações, o aumentar ou diminuir de seu conteúdo não acarretam, em princípio, obrigação necessária de indenizar ou ilicitude por si só ${ }^{16}$, mas mera potencialidade empíricocontingencial, a ser densificada por cada caso concreto.

Todas estas questões atingem diretamente o tema da ordenação do território urbano, principalmente quando se leva em conta que o espaço urbano é antes de tudo propriedade urbana, seja pública ou privada, o que explica a relação umbilical entre estes temas, destacando-se aqui e novamente a ampliação das condições e possibilidades de gestão desta propriedade por parte do Poder Público e o dever de tolerância e suportabilidade por parte dos seus titulares privados, em nome exatamente da segurança, do bem estar da população e da sustentatibilidade do desenvolvimento equilibrado do meio ambiente natural e construído (LEFÈBVRE, 1992).

O referido Estatuto da Cidade aprofundou a regulamentação da ocupação da Urbe, buscando justamente dar maior concretização às previsões constitucionais destacadas acima, e o fez bem, haja vista os déficits históricos neste âmbito e mesmo diante da ausência de políticas públicas no particular.

A despeito disto, a especulação imobiliária só tem se alastrado em várias partes do globo, em especial no Brasil, gerando exclusão social e ainda maior concentração de capital e renda, como bem adverte Bollaffi (1979). Ao lado disto, tem-se ampliado a importância de o Estado desenvolver mecanismos de monitoramento, controle e responsabilização em face dos riscos e violações a estas normas de Direito Público indisponíveis que até agora citamos, tanto o Poder Executivo, como o Legislativo e o Judiciário.

O caso que vamos analisar agora é típico de improbidade administrativa no âmbito urbanístico, que deve ser evitado a todo o custo.

O caso em avaliação trata de Apelação Cível no70073361768, julgada pela 21a Câmara Cível do Tribunal de Justiça do Estado do Rio Grande do Sul, em 10 de maio de 2017, tendo a relatoria do Des. Marco Aurélio Heinz, envolvendo situação em que o então Prefeito da cidade de Cruz Alta, tomou a iniciativa de desapropriar área de terra rural, para fins de utilidade

16 Retroagindo à função social da propriedade, essa leva, especificamente, a que o titular seja obrigado a "fazer", a valer-se de seus poderes e faculdades, no sentido do bem-comum. A função social da propriedade corresponde, desta forma, a uma concepção também comissiva do uso da propriedade. Neste sentido, ver o trabalho de DI LORENZO, Italo. Diritto Urbanistico. Turim: UTET, 1998, p.48. 
pública do Município, sabendo que pertencia a membro da família, embora constasse no álbum imobiliário outro proprietário.

A prova recolhida na instrução revelou, efetivamente, que o acusado tinha plena consciência de que o imóvel desapropriado, para fins de utilidade pública, pertencia de fato a seu irmão, bem como aos herdeiros de Atílio Fontana, pai destes.

A despeito do imóvel ter tido, ao final, destinação pública à municipalidade, nos termos da Lei local no 949/2013, continuando como horto florestal, parte para guardar equipamentos da patrulha agrícola e parte utilizada como arruamento. Além disto, o valor pago pela área desapropriada ( $\mathrm{R} \$ 90.000,00)$ correspondeu ao valor de mercado, conforme informação prestada pelo engenheiro do Ministério Público, da Unidade de Assessoramento Ambiental, tudo levando a crer que a conduta infracional imputada ao réu não acarretou prejuízo ao erário, nem caracterizou desvio de finalidade.

Todavia, restou nos autos inafastável a intenção do ex-Prefeito de desapropriar área de terra pertencente à família, amoldando-se sua conduta ao disposto no art.11, da Lei 8.429/1992, revelando violação explícita dos deveres de imparcialidade e honestidade, além do que violando os objetos protetivos desta Lei referidos acima.

É de se ver que condutas ímprobas enquadradas nas hipóteses deste art.11, da Lei de Improbidade, sujeita o infrator ao ressarcimento do dano, se houver; suspensão dos direitos políticos de três a cinco anos; pagamento de multa civil de até cem vezes o valor da remuneração percebida pelo agente e proibição de contratar com o Poder Público ou receber benefícios, devendo o Poder Judiciário levar em conta na dosimetria destas sanções a extensão do dano causado, assim como o proveito patrimonial obtido pelo agente (art. 12, § único, da Lei 8.429/1992), atuando com juízos de proporcionalidade e razoabilidade em face de todos estes contextos.

A partir destes elementos, o Tribunal, neste caso, dando relevo à inexistência de prejuízo ao erário e proveito econômico ao acusado, entendeu que a decisão de primeiro grau que determinou ao réu a suspensão dos direitos políticos e pagamento de multa equivalente a dez vezes a remuneração por ele percebida na condição de Prefeito Municipal, afastou-se da proporcionalidade e razoabilidade referidas, razão pela qual deu parcial provimento ao apelo, para excluir da condenação a pena de suspensão dos direitos políticos, reduzindo a pena de multa para três (3) vezes a remuneração percebida pelo ex-Prefeito, como descrita na sentença recorrida. 
Ou seja, restou configurada a improbidade no agir do Prefeito Municipal, e muito bem, cumprindo o Judiciário sua função restauradora da moralidade e do interesse público indisponível.

\section{CONCLUSÃO}

No plano da filosofia contemporânea, Habermas (1986) lembra que os trabalhos de sistematização dos juristas especializados tornaram consciente o processo de validade póstradicional do direito (antes fundado pela tradição e pelo carismo weberiano), fazendo com que as diferentes proposições jurídicas tivessem que ser fundamentadas como parte integrante de uma ordem jurídica tornada compreensível a partir de normas que se encontram expostas, sempre, a exames discursivos. ${ }^{17}$

Esta ordem jurídica, por sua vez, só é legítima - na reflexão habermasiana e para mim se estiver fundada numa relação interna entre moral e direito. Mas que relação é esta? É a relação na qual o universo moral constituído como processo histórico (e não natural) opera fundacionalmente na estratificação do direito moderno, notadamente através de suas regras e princípios.

Daí a importância das chamadas normas jurídicas principiológicas, pois que representam a legitimidade das escolhas públicas civilizatórias no que diz com que tipo de Sociedade se pretende viver, e com que procedimentos. Pode-se dizer até que:

L'ordine normativo ha imposto la sua verità, la verità del legislatore che diviene l'unica verità in grado di salvaguardare il bene comune, ovvero il proghetto che normalizza la convivenza. La verità normativa diventa, in questo senso, una strategia di aggregazione e di riconoscimento, sia dal punto de vista terminologico e concettuale, sia dal punto de vista pratico e concreto (RUFINO, 2012, p. 17, grifos próprios).

Quando tais normas são violadas, é a própria matriz criativa do social que se vê atacada, instabilizando as bases do convívio societal e instalando ambiências de insegurança - quebra da

\footnotetext{
${ }^{17}$ De pronto Habermas (1986, p.29, grifos próprios) esclarece, para já se distinguir de Weber, que ele não reconheceu o núcleo moral do direito formal burguês, porque entendia as intelecções morais, sempre, como orientações axiológicas subjectivas; valores equivalentes a conteúdos não mais realizáveis e, no futuro, impossíveis de compatibilizar com o carácter formal do direito. Ele não distinguiu entre a preferência de valores, que se recomendam, por assim dizer, como sendo mais importantes do que outros valores dentro de determinadas tradições e formas de vida culturais, e entre a validade deôntica de normas, que obrigam, separou a avaliação axiológica, que espalha, em toda a extensão, conteúdos axiológicos concorrentes, do aspecto formal da obrigação ou validade de normas que, de forma alguma, varia com os conteúdos normativos. Em resumo, ele não tomou a sério o formalismo ético.
} 
confiança - na Ordem Democrática e em suas instituições e momentos conformadores, abrindo espaços para o caos mitigador de Direitos e Garantias Fundamentais, públicos e privados.

Observa-se, dessa forma, que o conceito de moralidade/probidade é determinante de regras de conduta dos atores públicos, ou seja, traça linhas de comportamentos para o administrador, fazendo com que este, ao realizar seus atos, observe, além dos elementos constitutivos próprios de cada um, a eficácia e eficiência dos mesmos, de forma transparente, no plano dos compromissos e vinculações político-jurídicas já existentes.

Por outro lado, a identificação da compatibilidade da atividade administrativa com aqueles vetores é matéria complexa que conduz a situações singulares, dotadas de sutilezas que desafiam o aplicador e intérprete do direito. Sobrinho (2012) ${ }^{18}$, numa perspectiva mais pragmática, elenca quatro hipóteses que podem configurar quebra ao princípio sob comento: a) a do fato não justificar o ato, viciando-o na origem; b) a do ato não corresponder ao fato, desviando-se da causa; c) a do fato não exteriorizar motivos determinantes categóricos; d) a do ato não formalizar regras jurídicas estabelecidas.

É tão evidente a relação entre moralidade e probidade - e, por sua vez, improbidade administrativa - que Marcelo Figueiredo sustenta, com razão, que a probidade é espécie do gênero moralidade administrativa, nos termos do art. 37, caput, e seu $\S 4^{\circ}$, da Constituição Federal de 1988, eis que o núcleo da probidade estaria associado ao princípio da moralidade administrativa (FIGUEIREDO, 1995). Na mesma direção vai Silva (2010, p. 653), quando assevera:

[...] é uma forma de moralidade administrativa que mereceu consideração especial pela Constituição, que pune o ímprobo com a suspensão dos direitos políticos (art. $37, \S 4 \div$ ). A probidade administrativa consiste no dever de o 'funcionário servir a Administração com honestidade, procedendo no exercício de suas funções, sem aproveitar os poderes ou facilidades delas decorrentes em proveito pessoal ou de outrem a quem queira favorecer'. Cuida-se de uma imoralidade administrativa qualificada. A improbidade administrativa é uma imoralidade qualificada pelo dano ao erário e correspondente vantagem ao ímprobo ou a outrem. ${ }^{19}$

Di Pietro (2000) igualmente tem dito que os princípios moralidade e probidade têm pontos de confluência muito fortes, embora algumas leis façam referência separadamente a cada um deles. No entanto, quando se fala em improbidade como ato ilícito, como infração

\footnotetext{
18 Ver também o texto de MARTINS JR., Wallace Paiva. Probidade Administrativa. São Paulo: Saraiva, 2009.

19 Ver igualmente a abordagem mais ampliada que faz FREITAS, Juarez. O controle dos atos administrativos e os princípios jurídicos fundamentais. São Paulo: Malheiros, 2004, p.187-188.
} 
sancionada pelo ordenamento jurídico, deixa de haver sinonímia entre as expressões imoralidade e improbidade, porque esta tem um sentido mais amplo e mais preciso, por abranger não somente atos desonestos ou imorais, mas também atos ilegais. Efetivamente, na lei de improbidade administrativa, a lesão à moralidade é apenas uma das inúmeras hipóteses de atos de improbidade previstos em lei.

Caetano (1997, p.684) traz à colação bons argumentos para demarcar melhor o que envolve a probidade administrativa em casos concretos e ordinários de comportamento do gestor da coisa pública, a saber:

a) guarda fiel dos bens, direitos, interesses e valores públicos, abstendose do uso em proveito próprio ou de qualquer procedimento tendente a danificá-los, destruí-los ou diminuir-Ihes o valor; b) abstenção de proteger interesse, ainda que por interposta pessoa, em contrato a celebrar com a entidade a que esteja vinculado ou em negócio que dela dependa, particularmente se no exercício das funções puder exercer influência; c) proibição de aceite, por si ou interposta pessoa, de qualquer vantagem patrimonial, ou promessa futura, a fim de praticar ato influindo nas suas funções, ou mesmo abster-se de praticá-lo ou influir em outrem para obter esse comportamento, ou de fazer negócios pessoais com quem possa resultar dependência econômica comprometedora da sua função pública; d) vedação da exigência de particulares ou de consentimento de que se exijam deles quantias ou serviços legalmente indevidos e de abuso dos seus poderes para opressão da liberdade e interesses alheios ou para lesão do patrimônio privado sem fundamento legal; e) proibição de fazer negócio lucrativo com o provimento de alguém em cargo público; f) inadmissibilidade da circulação de listas de subscrição de donativos, em seu favor ou de terceiros, no recinto de trabalho ou de subscrever as que Ihe forem apresentadas; g) impossibilidade de advogar ou intermediar interesse particular nos serviços de sua competência; h) recusa do aceite de homenagens de subalternos ou particulares com interesses dependentes do exercício de sua função pública, salvo aposentadoria ou transferência.

No caso brasileiro, Osório (2007, p.142) propõe formulação conceitual caracterizadora e

adequada da improbidade administrativa a partir de feições mais pragmáticas:

(A) Categoria ético-normativa ligada à ideia de honra institucional, no marco da moralidade institucional republicana, que abarca patologias e transgressões normativas consubstanciadas em graves desonestidades e ineficiências funcionais dos agentes públicos, nas flutuações pertinentes à proporcionalidade enquanto postulado normativo e exposta ao processo hermenêutico institucionalizado num marco da razoabilidade. (B) Espécie de má gestão pública, em que podem existir múltiplas categorias, revestindo-se das notas da desonestidade ou ineficiência graves, passível de cometimento por ações ou omissões, dolosas ou culposas, por parte de agentes públicos no exercício de suas funções ou em razão delas, com ou sem a participação de particulares. (C) Exige a vulneração de regras legais e princípios (ou princípios e regras) constitucionais que presidem as 
funções públicas com grave agressão a direitos fundamentais e a normas de cultura administrativa vigentes; (D) Perfectibiliza-se a partir de normas sancionadoras em branco, que se integram e complementam por outras normas, e não pela simples violação a princípios e muito menos pela direta incidência da Lei 8.429/92.

Casos como o exposto na decisão do Tribunal de Justiça do Estado do Rio Grande do Sul evidenciam bem como doutrina e jurisprudência, em grande parte, estão aprimorando o debate e o controle da Administração Pública no particular, havendo muito o que discutir, mas agora sob premissas constitucionais e infraconstitucionais já bem consolidadas.

\section{REFERÊNCIAS BIBLIOGRÁFICAS}

AZEVEDO, Filadelfo. Destinação do imóvel. São Paulo: Max Limonad, 1957.

BANDEIRA DE MELLO, Celso Antônio. Elementos de Direito Administrativo. São Paulo: Revista dos Tribunais, 2000 a.

Discricionariedade e Controle Judicial. São Paulo: Malheiros, 2000 b.

Curso de Direito Administrativo. São Paulo: Malheiros, 2010.

Legalidade, Motivo e Motivação do Ato Administrativo. Revista de Direito Público, $\mathrm{n}$. 90/57, p.8, 11/2011.

o Controle Judicial dos Atos Administrativos. Revista de Direito Administrativo, n. 152/01, p.48, 06/2013.

O Desvio de Poder. Revista de Direito Administrativo, n. 172/1, 10/1988.

BENVILÁQUA, Clóvis. Direito das Coisas. Rio de Janeiro: Forense, 1956.

BOLLAFFI, Gabriel. Habitação e urbanismo: o problema e o falso problema. In: MARICATO, Erminia. (Org) A produção capitalista da casa (e da cidade) no Brasil Industrial. São Paulo: AlfaÔmega, 1979.

BRANCA, Giuseppe. Della Proprietà (arts. 957-1099). Bolonha: Zanichelli, 1957.

CAETANO, Marcello. Manual de Direito Administrativo. Coimbra: Almedina, 1997.

CÍCERO. Dos Deveres. São Paulo: Martin Claret, 2001.

CORTINA, Adela. Hasta un pueblo de demonios. Ética pública y sociedad. Madrid: Taurus, 1998.

DANTAS, Santiago. O Conflito de Vizinhança e sua Composição. Rio de Janeiro: Globo, 1939.

DI LORENZO, Italo. Diritto Urbanistico. Turim: UTET, 1998.

DI PIETRO, Maria Sylvia. Direito Administrativo. São Paulo: Atlas, 2000.

ESPINOSA, Roberto Moreno. La ética en la gobernabilidad democrática. Ponencia presentada durante el Congreso Internacional de Cultura y Sistemas Jurídicos Comparados. México: UNAM, Febrero, 2004. 
FIGUEIREDO, Marcelo. Probidade Administrativa. São Paulo: Malheiros Editores, 1995. O controle da moralidade na Constituição. São Paulo: Malheiros, 1999.

FREITAS, Juarez. Discricionariedade Administrativa e o Direito Fundamental à Boa Administração Pública. São Paulo: Malheiros, 2007.

GANDOLFO, Orlando Carlos. Limitações da propriedade. Revista dos Tribunais. V. 421. São Paulo: RT, 1970.

GARCIA E; ALVES, R. P. Improbidade administrativa. Rio de Janeiro: Lúmen Júris, 2002.

GONÇALVES, Luiz da Cunha. Tratado de Direito Civil. São Paulo: Limonad, 1956.

HABERMAS, Jürgen. Direito e Moral. Instituto Piaget: Lisboa. 1986.

HEDEMANN, Justus Wilhelm. Tratado de Derecho Civil. Madrid: Civitas, 1987.

LEAL, Rogério Gesta. Perspectivas do direito adquirido constitucional contra o Estado Democrático de Direito. Revista do Direito, n. 23, Santa Cruz do Sul - Editora da UNISC, 2006.

Estado, Administração Pública e Sociedade: novos paradigmas. Porto Alegre: Livraria do Advogado, 2009.

LEFÈBVRE, Henry. The production of space. London: Blackwell, 1992.

MARZUOLI, Carlo. Fenomeni Corruttivi e Pubblica Amministrazione: più discipline, un unico obiettivo. In: PALAZZO, Francesco. (Org.). Corruzione Pubblica. Firenze: Firenze University Press, 2011.

MATTARELLA, Bruno. Le regole dell’onestà. Bologna: Daltricce, 2012.

MERLONI, F.; VANDELLI, L. (Org.). La corruzione amministrativa: cause, prevenzione e rimedi. Firenze: Firenze University Press, 2010.

MORIN, Gastón. La revolte des fait contre le Code. Paris: FDL, 1990.

MUÑOZ, Jaime Rodriguez-Arana. La Dimensión Ética. Madrid: Dykinson, 2001.

OCDE. La Ética en el servicio público - cuestiones y prácticas actuales. Madrid: Ministerio de Administraciones Públicas/Instituto Nacional de Administración Pública - INAP.

La ética en el servicio público. Disponível em: <http://www.inap.org.mx/portal/images/RAP/la\%20etica\%20en\%20el\%20servicio\%20publico.p df>. Acesso em: 16 jan. 2013.

PAOLO, Mauro. Corruption and Growth. Quarterly Journal of Economics 110 (August): 681-712. 1995.

PAZZAGLINI FILHO, M; ROSA, M. F. E; FAZZIO JR., W. Improbidade Administrativa: Aspectos Jurídicos na defesa do Patrimônio Público. São Paulo: Atlas, 1999. 
RIPERT, George. La régle morale dans les obligations civiles. Paris: Dalloz, 1984.

RUFINO, Annamaria. II Diritto delle Garanzie. In: TEUBNER, G; RUFINO, A. II Diritto Possibile. Milano: Guerini, 2012.

SILVA, José Afonso da. Curso de Direito Constitucional. São Paulo: Malheiros, 2010.

SOBRINHO, Manoel de Oliveira Franco. O Princípio Constitucional da Moralidade Administrativa. Curitiba: Genesis Editora, 1993.

VANNUCCl, Antonio. La corruzione nel sistema político italiano a dieci anni da mani pulite. In: FORTI, Gabrio (Org.). Il prezzo della tangente: la corruzione come sistema a dieci anni da mani pulite. Milano: Vita e Pensiero, 2003.

Trabalho enviado em 03 de junho de 2017.

Aceito em 10 de julho de 2017. 